\title{
Astronomy in Venezuela
}

\author{
Patricia Rosenzweig \\ Universidad de Los Andes, Facultad de Ciencias, Departamento de \\ Física, Grupo de Astrofísica Teórica (GAT), Mérida, Venezuela. \\ e-mail: patricia@ciens.ula.ve
}

\begin{abstract}
Since the installation of the Observatorio Cagigal in Caracas, astronomy in Venezuela has developed steadily, and, in the last few decades, has been strong. Both theoretical and observational astronomy now flourish in Venezuela. A research group, Grupo de Astrofisica (GA) at the Universidad de Los Andes (ULA) in Mérida, started with few members but now has increased its numbers and undergone many transformations, promoting the creation of the Grupo de Astrofísica Teórica (GAT), the Grupo de Astronomía, the Centro de Astrofísica Teórica (CAT), and with other collaborators initiated the creation of a graduate study program (that offers master's and doctor's degrees) in the Postgrado de Física Fundamental of ULA. With the financial support of domestic Science Foundations such as CONICIT, CDCHT, Fundacite, and individual and collective grants, many research projects have been started and many others are planned. Venezuelan astronomy has benefitted from the interest of researchers in other countries, who have helped to improve our scientific output and instrumentation. With the important collaboration of national and foreign institutions, astronomy is becoming one of the strongest disciplines of the next decade in Venezuela.
\end{abstract}

\section{Introduction}

The history and development of the astronomy in Venezuela has been reviewed by some authors in Spanish (Stock, 1981; Olivares, 1986; Hubschmann, 1988; Quintero, 1989; Chalbaud, 1990). However the reader is referred to Inglis (1961) and Alvarez and MacConnell (1978) who give partial accounts in English. On the basis of these works, a brief account will be given in this short communication.

It can be said that astronomy began in Venezuela when the first observatory of the country was installed in Caracas in 1888 by Juan M. Cagigal (Hubschmann, 1988), today known as Cagigal Observatory after its founder. At that time, Caracas was a suitable site for an observatory, not only because the minimal amount of pollution and light contamination provided appropriate atmospheric conditions, but also because the city is the capital. Since then, this observatory has been in operation, serving mainly for astronomical observa- 
tions, legal time, and, in addition, for meteorological measurements. From 1888 to 1958 the observatory was under the administration of the Ministry of Education; since then and up to the present, it has been under the administration of the Venezuelan Navy.

To improve the Observatory's equipment, in 1953 it was proposed to buy sophisticated telescopes from the Askania and Zeiss companies. At that time, the Director of the Observatory was Eduardo Röhl who was the principal supporter of the Observatory's development. The major instruments were the $1.5-\mathrm{m}$ Schmidt camera, the 1-m coudé-Cassegrain reflector, a refractor of $65-\mathrm{cm}$ aperture (10.5 $\mathrm{m}$ in length), and the double astrograph (each of $50-\mathrm{cm}$ aperture). Unfortunately, these instruments could not be installed in Cagigal Observatory because light contamination and atmospheric pollution in Caracas began to be a major problem from the 1960s onwards. Instead, it was recommended to locate these instruments in another observatory to be built in a suitable place with better conditions. Two major factors contributed to modify this initial project, namely, the death of Röhl in 1959 and the political situation of the nation, which led to a change in the government system in 1958.

The construction of a second and bigger observatory was necessary to install the main instruments mentioned above. In 1962 a commission of AURA (Edmondson, 2000) recommended the installation of this new observatory in the Venezuelan Andes, specifically in Mérida State, taking into account two major factors: (i) the Mérida sky presents good seeing compared to other places in the country, and (ii) the logistical support of a large university (the Universidad de Los Andes) that could assist in the creation of astronomy and astrophysics studies in cooperation with the observatory.

It was not until 1970 that the construction of this second observatory in Venezuela began, operated this time independently from the Cagigal Observatory, and under the supervision and support of the National Council for Scientific and Technological Research (CONICIT). Based on this introductory historical review, the purpose of this paper, as mentioned before, is to give a report of the present status of Venezuelan astronomy and future national and international projects.

\section{Present Status of Venezuelan Astronomical Research and Teaching}

This second, modern observatory was built next to a small village in Mérida state called Llano del Hato, from which the name "Observatorio Nacional de Llano del Hato" was derived. In order to make a final decision, the Universidad de Los Andes (ULA) provided the premises for the storage of the instruments and construction of four telescope buildings. Also, ULA provided qualified personnel to examine whether or not the ground could hold the weight of the instruments mentioned (Stock, 1981). At the same time of the creation of the Observatorio Nacional de Llano del Hato, the Fundación Centro de Investigaciones en Astronomía "Francisco J. Duarte" (CIDA) was also created to manage the Observatory. On the other hand, in the Universidad de Los Andes, the birth of the Astrophysics Research Group within the Physics Department of the Faculty of Science took place. 
This Group, consisting of students, instructors, and professors, worked closely with Dr. J. Stock, the Director-in-Chief of the Observatory project to complete the remaining work. With the purpose of starting a teaching program in astronomy, courses in different subjects of this discipline were given by foreign and national astronomers. Also, some theses were offered and consequently, in 1975, students began to obtain their undergraduate degrees in physics with a major in astronomy. Many of these students had to travel to other countries in order to obtain a third-level degree. When they returned, interests of several sorts emerged. Thus the study of theoretical astrophysics was considered to be of high interest. In this way, the original Astrophysics Group gave rise to another group that focused on this discipline (the Group in Theoretical Astrophysics, GAT). The interest grew more and more and a "critical mass" of well-trained specialists in astronomy stimulated the creation of graduate studies in astronomy. In 1991 the Graduate Program called "Postgrado en Astronomía y Astrofísica (PAAS)" was created and offered the master's degree. Then, in 1995 the doctoral degree was offered for the first time. Because this program included many specific areas, some of which were only marginally related to astronomy, and because it started to involve collaboration from other educational institutes of the same level, this graduate program changed its name in 1997 to Postgrado en Física Fundamental (PFF). This program comprises 21 professors from ULA and from other institutions. Since the creation of the PAAS (now PFF), 13 master's and 1 doctoral degrees have been awarded. Now the program has an enrolment of approximately 19 master's and 10 doctoral students.

Parallel to the creation of the Graduate Study Program, the creation of a Center of Theoretical Astrophysics (CAT) was established in the Faculty of Science of the Universidad de Los Andes (ULA). The Group of Theoretical Astrophysics (GAT), together with the CAT, involve the collaboration of approximately 22 members, not only from ULA but also from other universities and research institutes, such as Instituto Venezolano de Investigaciones Científicas (IVIC), Universidad Simon Bolívar (USB), and Universidad Central de Venezuela (UCV).

The lines of research are very diversified. Some of them, included either in the PFF, in the GAT, or in the CAT are, astrophysical plasmas, the interstellar medium, solar system, observational astronomy (spectroscopy, photometry, astrometry, etc.), relativistic astrophysics, quantum theory of fields, chaos and non-linear dynamics, chemistry and physics.

\section{Ongoing Scientific Projects}

Venezuelan astronomers have opened different collaborations with institutions abroad. These collaborations have also improved the instruments in the Observatory. For instance, the QUEST project is a collaborative effort of the Physics and Astronomy Departments at Yale University, Indiana University, CIDA and the University of Los Andes, to study gravitational lensing of quasars. At this time, QUEST has designed and built a large-area CCD mosaic camera with 16 CCDs, This camera has been installed on the Schmidt telescope of the Observatory and is now routinely taking high-quality data. Another important collaboration has been established with the University of Canterbury in New 
Zealand. Specifically, the spectroscopic study of novae and supergiant stars has been based on spectra taken in the Observatory and the Mt. John University Observatory in New Zealand. Additionally, collaboration has been established with UNAM in México in which studies of Cepheid stars are based on photometric data from the Observatory and the San Pedro Mártir Observatory in México.

Many other collaborations with European observatories and research centers have also been established. For example, theoretical work in physics is being undertaken with the Abdus Salam International Center for Theoretical Physics. There are many more projects and all of them promising high-quality researche to be published in several scientific periodicals.

\section{Future Perspectives}

In spite of the economic crisis, which Venezuela has been facing for a long time, astronomers, as well as other researchers, can obtain financial support from several organizations. The most important national agency that supports science is CONICIT along with its local regional offices called Fundacite. Also, in each university there are internal agencies such as, the CDCHTs, the University Scientific Exchange Program, and the International Inter-Institutional Relations Office that provides a substantial financial assistance as well. Besides, each qualified researcher can count on grants provided by their respective institution.

\section{Final Comments}

From my point of view, even though Venezuela is a developing country and thereby subjected to many crises (especially of the financial kind), the organizations involved in the progress of science have given, and are still giving, substantial priority to the consolidation of the astronomical heritage. Above all, taking into account that even though any scientific enterprise is undertaken with great difficulty, the scientific output is of a high standard as is demonstrated by the different scientific articles and publications found in recognized periodicals. In part, this high standard of production results from the efforts by several faculty members who had the opportunity to obtain their doctorates abroad and returned to the country some time ago; also from many projects that are active at the present time with other colleagues overseas, and from the work of colleagues who have obtained their degrees from our graduate programs as well.

Acknowledgments. Special thanks to the IAU for their support and kind invitation to the Special Session. I am also grateful to Dr Alan Batten and Prof. John Hearnshaw for their guidance throughout this work and the Session. I would like also to thank Dr. Marcos Peñaloza for assistance in preparing the manuscript and useful discussions. Finally, to the CDCHT-ULA and CONICIT, both in Venezuela, for their financial support. 


\section{References}

Alvarez, H., and MacConnell, D.J. 1978. Astronomy in Venezuela Today, Sky and Telescope, 55, 103.

Chalbaud, P. 1990, Indicios de la Astronomía Moderna en Venezuela: El Proyecto de Eduardo Röhl Aportes para su Estudio, Thesis, Bachelor Degree, Universidad de Los Andes.

Edmondson, F.K. 2000, private communication.

Hubschmann, K., 1988, Observatorio Cagigal: Cien Años de Historia y Ciencia, Colección: Cuadernos Lagoven, Caracas, Editora Venegráfica.

Inglis, S.J. (1961). Astronomy in Venezuela, Sky and Telescope, 22, 251.

Olivares, A. E. 1986, Dr. Luis Ugueto, Ingeniero, Astrónomo y Profesor, Caracas, Academia de Ciencias Físicas, Matemáticas y Naturales.

Quintero, I. 1989, Del Observatorio Cagigal al CIDA: Dos Instituciones Científicas en la Historia de la Ciencia en Venezuela, Caracas, Fondo Editorial Acta Científica Venezolana

Stock, J. 1981, Astronomía en Venezuela, Revista Mexicana de Astronomía y Astrofísica, 6, 13.

\section{Discussion}

Mahoney asked about the policy of the new Venezuelan government for astronomy and Rosenzweig replied that it was to continue with the budgetary plans. Tancredi asked if the QUEST instrument on the Schmidt telescope was available for programs other than the microlensing search. Rosenzweig replied that it was also used, among other programs, to search for minor planets, supernovae, and to study variable stars. Fierro asked if Venezuelan degree courses were open to students from other countries (especially in Latin America) and Rosenzweig confirmed that they are. 